\title{
Association of MYLIP rs3757354 SNP and several environmental factors with serum lipid levels in the Guangxi Bai Ku Yao and Han populations
}

Ting-Ting Yan, Rui-Xing Yin*, Qing Li, Ping Huang, Xiao-Na Zeng, Ke-Ke Huang, Dong-Feng Wu and Lynn Htet Htet Aung

\begin{abstract}
Background: The association of rs3757354 single nucleotide polymorphism (SNP) in the E3 ubiquitin ligase myosin regulatory light chain-interacting protein (MYLIP, also known as IDOL) gene and serum lipid levels is not well known in the general population. The present study aimed to detect the association of rs3757354 SNP and several environmental factors with serum lipid levels in the Guangxi Bai Ku Yao and Han populations.

Method: A total of 627 subjects of Bai Ku Yao minority and 614 participants of Han nationality were randomly selected from our stratified randomized cluster samples. Genotyping of the rs3757354 SNP was performed by polymerase chain reaction and restriction fragment length polymorphism combined with gel electrophoresis, and then confirmed by direct sequencing.

Results: The levels of serum total cholesterol (TC), high-density lipoprotein cholesterol (HDL-C), low-density lipoprotein cholesterol (LDL-C), apolipoprotein (Apo) Al and ApoB were lower in Bai Ku Yao than in Han $(P<0.05$ 0.001). The frequency of $G$ allele was $49.92 \%$ in Bai Ku Yao and $56.27 \%$ in Han $(P<0.05)$. The frequencies of AA, GA and GG genotypes were $25.52 \%, 49.12 \%$ and $25.36 \%$ in Bai Ku Yao, and $19.87 \%, 47.72 \%$ and $32.41 \%$ in Han $(P<$ $0.05)$; respectively. There were no significant differences in the genotypic and allelic frequencies between males and females in both ethnic groups. The levels of HDL-C in Bai Ku Yao were different among the genotypes $(P<0.05)$, the $G$ allele carriers had higher serum $\mathrm{HDL}-\mathrm{C}$ levels than the $\mathrm{G}$ allele noncarriers. The levels TC, HDL-C and ApoAl in Han were different among the genotypes $(P<0.05$ for all), the participants with GA genotype had lower serum TC, $\mathrm{HDL}-\mathrm{C}$ and ApoAl levels than the participants with AA genotype. These findings were found only in females but not in males. The levels of TG and HDL-C in Bai Ku Yao were correlated with the genotypes, whereas the levels of TC in Han, and TC, LDL-C in Han females were associated with the genotypes $(P<0.05$ for all). Serum lipid parameters were also correlated with age, sex, alcohol consumption, cigarette smoking, blood pressure, and body mass index in both ethnic groups $(P<0.05-0.001)$.

Conclusions: The present study suggests that the MYLIP rs3757354 SNP is associated with serum TC, HDL-C and ApoAl levels in the Bai Ku Yao and Han populations. But the association is different between the two ethnic groups.
\end{abstract}

\footnotetext{
* Correspondence: yinruixing@yahoo.com.cn

Department of Cardiology, Institute of Cardiovascular Diseases, the First

Affiliated Hospital, Guangxi Medical University, University, 22 Shuangyong

Road, Nanning 530021 Guangxi, People's Republic of China
} 


\section{Introduction}

Many epidemiological and clinical studies have shown that dyslipidemia is strongly associated with an increased risk of coronary artery disease (CAD) [1-5]. It is generally agreed that dyslipidemia is a complex trait caused by genetic factors and multiple environmental risk factors such as diet, alcohol consumption, cigarette smoking, obesity, physical inactivity, hypertension and their interactions [6-9]. Family studies have shown that in many populations, genetic polymorphisms could account for half of the variation in serum lipid phenotypes $[10,11]$, and it is clear that serum lipid levels are strongly influenced by the genetic constitution of each individual.

Recent genome-wide association studies (GWAS) in different populations have identified more than 95 loci influence plasma lipid levels [12-23]. These studies evaluated large samples of normolipidemic individuals and showed that several new single nucleotide polymorphisms (SNPs) had replicable modest associations with plasma concentrations of total cholesterol (TC), triglyceride (TG), low-density lipoprotein cholesterol (LDL-C), and high-density lipoprotein cholesterol (HDL-C) [1518]. In addition, GWAS also discovered a number of novel loci that influence serum lipid phenotypes [23-25]. One of these newly identified SNPs is the E3 ubiquitin ligase myosin regulatory light chain-interacting protein (MYLIP, also known as IDOL) gene. MYLIP locates on chromosome 6p22.3 which stimulates ubiquitination of the low-density lipoprotein receptor (LDLR) on its cytoplasmic tail, thereby directing its degradation [24]. It is also known as post-transcriptional regulator of LDLR abundance [26-33]. The LXR-MYLIP-LDLR pathway provides a complementary pathway to sterol regulatory element-binding proteins for the feedback inhibition of cholesterol uptake [34]. Several SNPs including MYLIP rs9370867, rs3757354 and rs2327951 have been associated with human plasma cholesterol [35]. However, the rs3757354 SNP has not been reported in prior GWAS for plasma lipid concentration [24]. Teslovich et al. [23] demonstrated 95 loci that showed genome-wide significant association with blood lipid, and rs3757354 was shown significant association with LDL-C and TC. Weissglas-Volkov et al. [35] demonstrated that N342S in MYLIP was associated with higher TC levels in Mexican dyslipidemic individuals. However, Santos et al. [36] involved MYLIP p.N342S polymorphism is not associated with lipid profiles in the Brazilian population and indicated that further studies are needed to reaffirm the MYLIP polymorphism function. Besides, Banka et al. [37] and Kararigas et al. [38] reported that MYLIP is a sex-specific element influencing contractile function. Thus, it would be interesting to characterize the full impact of the relationship between rs3757354 and serum lipid levels.
China is a multiethnic country. There are 56 ethnic groups. Han nationality is the largest ethnic group, and Yao nationality is the eleventh largest minority among the 55 minority groups according to the population size. Bai Ku Yao (White-trouser Yao), an isolated subgroup of Yao nationality, is named so because all the men wear white knee-length knickerbockers. The population size is about 30000 . Because of isolation from the other ethnic groups, the special customs and cultures including their clothing, intra-ethnic marriages, ballad, funeral, bronze drum, spinning top, dietary habits, and corn wine and rum intakes are still completely preserved to the present day. In several previous studies, we found that the serum lipid concentrations were lower in Bai Ku Yao than in Han from the same region $[7,8,39]$. This ethnic difference in serum lipid profiles is still unknown. We hypothesized that there may be significant differences in some genetic polymorphisms between the two ethnic groups [40-44]. Therefore, the aim of the present study was to detect the association between rs3757354 SNP in the MYLIP gene and several environmental factors with serum lipid profiles in the Guangxi Bai Ku Yao and Han populations.

\section{Materials and methods \\ Participants}

The participants in the present study included 627 individuals of Bai $\mathrm{Ku}$ Yao who live in Lihu and Baxu villages in Nandan County, Guangxi Zhuang Autonomous Region, People's Republic of China. They were randomly selected from our previous stratified randomized cluster samples [7]. The ages of the participants ranged from 17 to 80 years, with an average age of $40.59 \pm 14.21$ years. There were 303 males (48.3\%) and 324 females (51.7\%). All participants were rural agricultural workers. During the same period, a total of 614 people of Han nationality who reside in the same villages were also randomly selected from our previous stratified randomized cluster samples. The mean age of the subjects was $40.94 \pm 15.56$ years (range 15 to 86 ). There were 294 men $(47.9 \%)$ and 320 women $(52.1 \%)$. All of them were also rural agricultural workers. All study subjects were essentially healthy and had no evidence of any chronic illness, including hepatic, renal, or thyroid. The participants with a history of heart attack or myocardial infarction, stroke, congestive heart failure, diabetes or fasting blood glucose $\geq 7.0$ $\mathrm{mmol} / \mathrm{L}$ determined by glucose meter were excluded from the analyses. The participants were not taking medications known to affect serum lipid levels (lipidlowering drugs such as statins or fibrates, beta-blockers, diuretics, or hormones). The experimental design was approved by the Ethics Committee of the First Affiliated Hospital, Guangxi Medical University. All participants in this study had provided written informed consent. 


\section{Epidemiological survey}

The survey was carried out using internationally standardized methods, following a common protocol [45]. All participants underwent a complete history, physical examination, and laboratory assessment of cardiovascular risk factors, including lifestyle factors, family history of myocardial infarction, hypertension and diabetes mellitus. Information on demographics, socioeconomic status, and lifestyle factors was collected with standardized questionnaires. The alcohol information included questions about the number of liangs (about $50 \mathrm{~g}$ ) of rice wine, corn wine, rum, beer, or liquor consumed during the preceding 12 months. Alcohol consumption was categorized into groups of grams of alcohol per day: $<25$ and $\geq 25$. Smoking status was categorized into groups of cigarettes per day: $<20$ and $\geq 20$. At the physical examination, several parameters, such as height, weight, and waist circumference were measured. Sitting blood pressure was measured three times with the use of a mercury sphygmomanometer after the subjects had a 5 -minute rest, and the average of the three measurements was used for the level of blood pressure. Systolic blood pressure was determined by the first Korotkoff sound, and diastolic blood pressure by the fifth Korotkoff sound. Body weight, to the nearest 50 grams, was measured using a portable balance scale. Subjects were weighed without shoes and in a minimum of clothing. Height was measured, to the nearest $0.5 \mathrm{~cm}$, using a portable steel measuring device. From these two measurements body mass index $\left(\mathrm{BMI}, \mathrm{kg} / \mathrm{m}^{2}\right)$ was calculated.

\section{Determination of serum lipid levels}

Venous blood samples $(5 \mathrm{~mL})$ were collected from all subjects after an overnight (at least 12 hours) fast. A part of the sample $(2 \mathrm{~mL})$ was collected into glass tubes and allowed to clot at room temperature, and used to determine serum lipid levels. Another part of the sample (3 $\mathrm{mL}$ ) was transferred to tubes with anticoagulate solution $(4.80 \mathrm{~g} / \mathrm{L}$ citric acid, $14.70 \mathrm{~g} / \mathrm{L}$ glucose, and $13.20 \mathrm{~g} / \mathrm{L}$ tri-sodium citrate) and used to extract DNA. The levels of TC, TG, HDL-C, and LDL-C in the samples were measured according to standard enzymatic methods. Serum apolipoprotein (Apo) AI and ApoB levels were detected by the immunoturbidimetric immunoassay. All determinations were performed with an autoanalyzer (Type 7170A; Hitachi Ltd., Tokyo, Japan) in the Clinical Science Experiment Center of the First Affiliated Hospital, Guangxi Medical University.

\section{DNA preparation and genotyping}

Genomic DNA was isolated from peripheral blood leukocytes using the phenol-chloroform method [40-44]. The extracted DNA was stored at $-80^{\circ} \mathrm{C}$ until analysis.
Genotyping of the rs3757354 SNP was performed by polymerase chain reaction and restriction fragment length polymorphism (PCR-RFLP). PCR amplification was performed using 5'-ACAGAGCAAAAGACCCTGT CTC-3' and 5'-AAAGAACTGTGTGTGGGAGGAT-3' (Sangon, Shanghai, People's Republic of China) as the forward and reverse primer pairs; respectively. Each amplification reaction system of a total volume of $25 \mu \mathrm{L}$, comprised $100 \mathrm{ng}(2 \mu \mathrm{L})$ of genomic DNA; $1.0 \mu \mathrm{L}$ of each primer $(10 \mu \mathrm{mo} 1 / \mathrm{L}) ; 12.5 \mu \mathrm{L} 2 \times \mathrm{Taq}$ PCR MasterMix (constituent: $0.1 \mathrm{U}$ Taq polymerase $/ \mu \mathrm{L}, 500 \mu \mathrm{M}$ dNTP each, $20 \mathrm{mM}$ Tris-HCl, pH 8.3, $100 \mathrm{mM} \mathrm{KCl,} 3$ $\mathrm{mM} \mathrm{MgCl}$, and stabilizers), and nuclease-free water 8.5 $\mu \mathrm{L}$. After initial denaturizing at $95^{\circ} \mathrm{C}$ for $5 \mathrm{~min}$, the reaction mixture was subjected to 30 cycles of denaturation at $95^{\circ} \mathrm{C}$ for $30 \mathrm{~s}$, annealing at $61^{\circ} \mathrm{C}$ for $45 \mathrm{~s}$ and extension $1 \mathrm{~min}$ at $72^{\circ} \mathrm{C}$, followed by a final 5 min extension at $72^{\circ} \mathrm{C}$. After electrophoresis on a $1.5 \%$ agarose gel with $0.5 \mu \mathrm{g} / \mathrm{mL}$ ethidium bromide, the amplification products were visualized under ultraviolet light. Then $10.0 \mathrm{U}$ of HaeIII restriction enzyme, $8 \mu \mathrm{L}$ nuclease-free water and $1 \mu \mathrm{L}$ of $10 \times$ buffer solution were added directly to the PCR products $(5 \mu \mathrm{L})$ and digested at $37^{\circ} \mathrm{C}$ overnight. After restriction enzyme digestion of the amplified DNA, genotypes were identified by electrophoresis on $2.0 \%$ agarose gel and visualized with ethidium-bromide staining ultraviolet illumination. Genotypes were scored by an experienced reader blinded to epidemiological data and serum lipid levels.

\section{DNA sequencing}

Six samples (AA, GA and GG genotypes in two; respectively) detected by the PCR-RFLP were also confirmed by direct sequencing. The PCR products were purified by low melting point gel electrophoresis and phenol extraction, and then the DNA sequences were analyzed in Shanghai Sangon Biological Engineering Technology \& Services Co., Ltd., People's Republic of China.

\section{Diagnostic criteria}

The normal values of serum TC, TG, HDL-C, LDL-C, ApoAI, ApoB levels and the ratio of ApoAI to ApoB in our Clinical Science Experiment Center were 3.10-5.17, $0.56-1.70, \quad 1.16-1.42, \quad 2.70-3.20 \mathrm{mmol} / \mathrm{L}, \quad 1.00-1.78$, $0.63-1.14 \mathrm{~g} / \mathrm{L}$, and $1.00-2.50$; respectively [40]. The individuals with TC $>5.17 \mathrm{mmol} / \mathrm{L}$ and/or TG $>1.70$ $\mathrm{mmol} / \mathrm{L}$ were defined as hyperlipidemic $[7,8]$. Hypertension was diagnosed according to the criteria of 1999 World Health Organization-International Society of Hypertension Guidelines for the management of hypertension [46,47]. The diagnostic criteria of overweight and obesity were according to the Cooperative Metaanalysis Group of China Obesity Task Force. Normal 
weight, overweight and obesity were defined as a BMI $<24,24-28$, and $>28 \mathrm{~kg} / \mathrm{m}^{2}$; respectively [48].

\section{Statistical analysis}

Epidemiological data were recorded on a pre-designed form and managed with Excel software. The statistical analyses were done with the statistical software package SPSS 13.0 (SPSS Inc., Chicago, Illinois). Quantitative variables were expressed as mean \pm standard deviation (serum TG levels were presented as medians and interquartile ranges). Qualitative variables were expressed as percentages. Allele frequency was determined via direct counting, and the standard goodness-of-fit test was used to test the Hardy-Weinberg equilibrium. Difference in genotype distribution between the groups was obtained using the chi-square test. The difference in general characteristics between two ethnic groups was tested by the Student's unpaired $t$-test. The association of genotypes and serum lipid parameters was tested by analysis of covariance (ANCOVA). Age, sex, BMI, blood pressure, alcohol consumption, and cigarette smoking were included in the statistical models as covariates. Multiple linear regression analyses adjusted for age, sex, BMI, blood pressure, alcohol consumption, and cigarette smoking were also performed to assess the association of serum lipid levels with genotypes $(\mathrm{AA}=1, \mathrm{GA}=2$, GG $=3$ ) and several environment factors. A $P$ value of less than 0.05 was considered statistically significant.

\section{Results}

\section{General characteristics and serum lipid levels}

The general characteristics and serum lipid levels between the Bai $\mathrm{Ku}$ Yao and Han populations are presented in Table 1. The levels of height, weight, systolic blood pressure, pulse pressure, serum TC, HDL-C, LDLC, ApoAI,and ApoB were lower in Bai Ku Yao than in Han $(P<0.05-0.001)$, whereas the percentage of subjects who smoked cigarettes or consumed alcohol was higher in Bai $\mathrm{Ku}$ Yao than in Han $(P<0.001)$. There were no significant differences in the levels of $\mathrm{BMI}$, diastolic blood pressure, serum TG, the ratio of ApoAI to ApoB and the ratio of male to female between the two ethnic groups $(P>0.05$ for all).

Table 1 The general characteristics and serum lipid levels in the Bai Ku Yao and Han populations

\begin{tabular}{|c|c|c|c|c|}
\hline Parameter & Bai Ku Yao & Han Chinese & $t\left(x^{2}\right)$ & $P$ \\
\hline Number & 627 & 614 & - & - \\
\hline Male/female & $303 / 324$ & $294 / 320$ & 0.024 & 0.910 \\
\hline Age (years) & $40.59 \pm 14.21$ & $40.94 \pm 15.56$ & -0.425 & 0.671 \\
\hline Height (cm) & $152.70 \pm 7.15$ & $154.76 \pm 8.22$ & -4.691 & 0.000 \\
\hline Weight (kg) & $52.05 \pm 7.28$ & $54.03 \pm 9.58$ & -4.084 & 0.000 \\
\hline Body mass index $\left(\mathrm{kg} / \mathrm{m}^{2}\right)$ & $22.28 \pm 2.39$ & $22.50 \pm 3.25$ & -1.349 & 0.178 \\
\hline Systolic blood pressure $(\mathrm{mmHg})$ & $119.69 \pm 17.23$ & $121.84 \pm 17.76$ & -2.169 & 0.030 \\
\hline Diastolic blood pressure (mmHg) & $75.94 \pm 9.58$ & $76.43 \pm 11.26$ & -0.821 & 0.412 \\
\hline Pulse pressure $(\mathrm{mmHg})$ & $43.75 \pm 12.86$ & $45.48 \pm 12.27$ & -2.423 & 0.016 \\
\hline \multicolumn{5}{|l|}{ Cigarette smoking [n (\%)] } \\
\hline Nonsmoker & $415(66.19)$ & $472(76.87)$ & & \\
\hline$<20$ cigarettes/day & $92(14.67)$ & $64(10.42)$ & & \\
\hline$\geq 20$ cigarettes/day & $120(19.14)$ & $78(12.70)$ & 17.463 & 0.000 \\
\hline \multicolumn{5}{|l|}{ Alcohol consumption [n (\%)] } \\
\hline Nondrinker & $331(52.19)$ & $417(67.91)$ & & \\
\hline$<25 \mathrm{~g} /$ day & $189(30.14)$ & $121(19.71)$ & & \\
\hline$\geq 25 \mathrm{~g} /$ day & $107(17.07)$ & $76(12.38)$ & 29.922 & 0.000 \\
\hline Total cholesterol (mmol/L) & $4.38 \pm 0.93$ & $4.77 \pm 0.99$ & -7.123 & 0.000 \\
\hline Triglyceride $(\mathrm{mmol} / \mathrm{L})$ & $0.99(0.66)$ & $1.04(0.74)$ & -1.605 & 0.109 \\
\hline $\mathrm{HDL}-\mathrm{C}(\mathrm{mmol} / \mathrm{L})$ & $1.70 \pm 0.42$ & $1.87 \pm 0.48$ & -6.751 & 0.000 \\
\hline $\mathrm{LDL}-\mathrm{C}(\mathrm{mmol} / \mathrm{L})$ & $2.57 \pm 0.78$ & $2.66 \pm 0.77$ & -1.978 & 0.048 \\
\hline Apolipoprotein (Apo) Al (g/L) & $1.33 \pm 0.32$ & $1.42 \pm 0.27$ & -5.196 & 0.000 \\
\hline ApoB (g/L) & $0.84 \pm 0.23$ & $0.90 \pm 0.22$ & -4.252 & 0.000 \\
\hline ApoAl/ApoB & $1.72 \pm 0.80$ & $1.67 \pm 0.52$ & 1.331 & 0.184 \\
\hline
\end{tabular}

$H D L-C$, high-density lipoprotein cholesterol; $L D L-C$, low-density lipoprotein cholesterol. The value of triglyceride was presented as median (interquartile range), the difference between the two ethnic groups was determined by the Wilcoxon-Mann-Whitney test. 


\section{Electrophoresis and genotypes}

After the genomic DNA of the samples was amplified by PCR and imaged by $1.5 \%$ agarose gel electrophoresis, the PCR products of 387 bp nucleotide sequences could be seen in the samples (Figure 1). The genotypes identified were named according to the presence or absence of the enzyme restriction sites. The presence of the cutting site indicates the $\mathrm{G}$ allele, while its absence indicates the $\mathrm{A}$ allele (cannot be cut). Thus, AA genotype is homozygote for the absence of the site (bands at $387 \mathrm{bp}$ ), GA genotype is heterozygote for the absence and presence of the site (bands at 387-, 306- and 81-bp), and GG genotype is homozygote for the presence of the site (bands at 306and 81- bp; Figure 2).

\section{Nucleotide sequences}

The results were shown as AA, GA and GG genotypes of the rs3757354 SNP by PCR-RFLP, the genotypes were also confirmed by sequencing (Figure 3); respectively.

\section{Genotypic and allelic frequencies}

The genotypic and allelic frequencies of rs3757354 SNP in the both ethnic groups are shown in Table 2. The genotype distribution followed the Hardy-Weinberg equilibrium. The $\mathrm{A}$ and $\mathrm{G}$ allele frequencies were $50.08 \%$ and $49.92 \%$ in Bai $\mathrm{Ku}$ Yao, and $43.73 \%$ and $56.27 \%$ in Han $(P<0.05)$; respectively. The frequencies of AA, GA and GG genotypes were $25.52 \%, 49.12 \%$ and $25.36 \%$ in Bai Ku Yao, and $19.87 \%, 47.72 \%$ and $32.41 \%$ in Han $(P<$ $0.05)$; respectively. There were no significant differences in the genotypic and allelic frequencies between males and females in both ethnic groups.

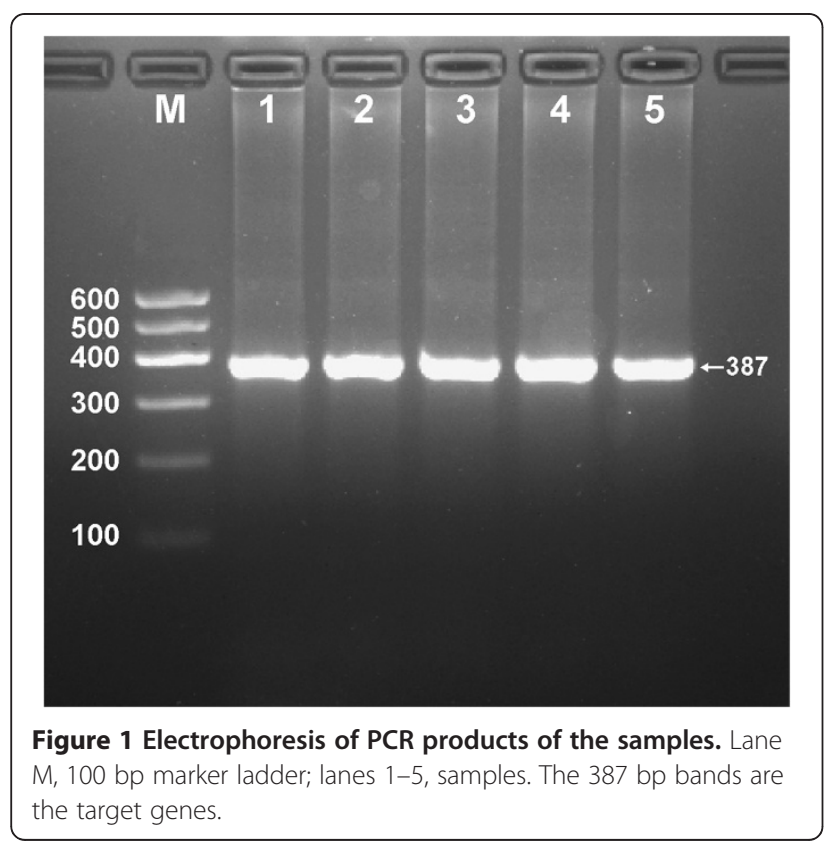

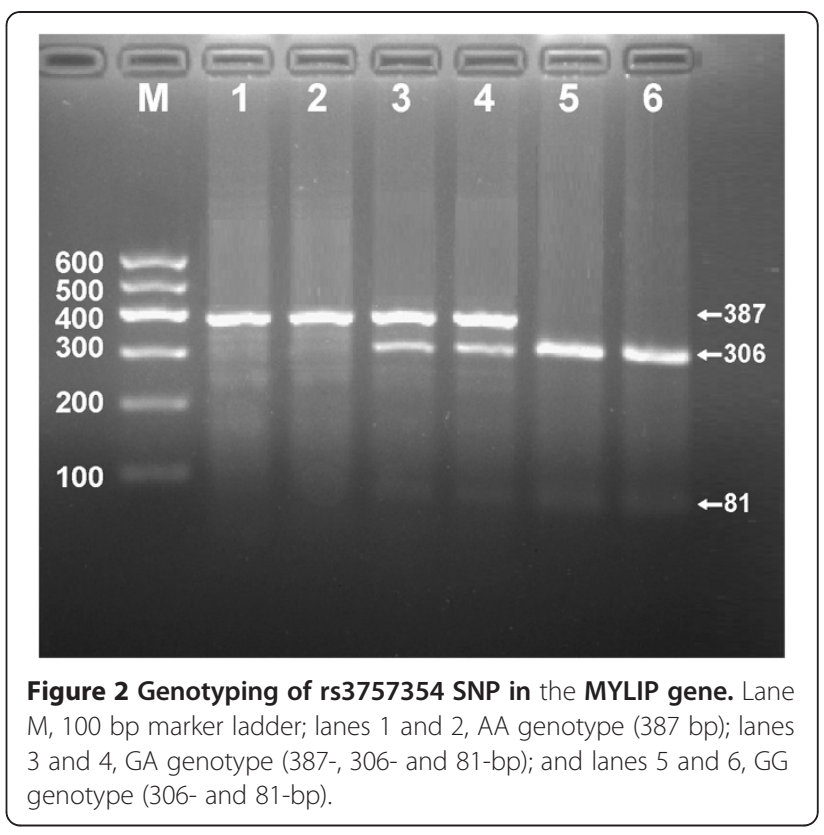

\section{Genotypes and serum lipid levels}

As shown in Table 3, the levels of HDL-C in Bai $\mathrm{Ku}$ Yao were different among the three genotypes $(P<$ 0.05), the $G$ allele carriers had higher serum HDL-C levels than the $\mathrm{G}$ allele noncarriers. For the Han population, the levels of TC, HDL-C and ApoAI among the three genotypes were different $(P<0.05)$, the subjects with GA genotype had lower serum TC, HDL-C and ApoAI levels than the subjects with AA genotype. When serum lipid parameters in Han were stratified according to sex, we showed that the levels of $\mathrm{TC}$, HDL-C and ApoAI in females but not in males were different among the AA, GA and GG genotypes $(P<$ $0.05)$, the participants with GA genotype had lower serum TC, HDL-C and ApoAI levels than the participants with AA genotype.

\section{Risk factors for serum lipid parameters}

Multiple linear regression analysis showed that serum TG and HDL-C levels in Bai Ku Yao were correlated with the genotypes of rs3757354 SNP $(P<0.05$ for each; Table 4), whereas the levels of TC in Han (Table 4), and TC, LDL-C in Han females (Table 5) were correlated with the genotypes $(P<0.05$ for all).

Serum lipid parameters were also correlated with several environmental factors such as age, gender, BMI, alcohol consumption, cigarette smoking, blood pressure in both ethnic groups $(P<0.05-0.001$; Table 4$)$.

\section{Discussion}

The present study shows that the levels of serum TC, HDL-C, LDL-C, ApoAI and ApoB were lower in Bai Ku Yao than in Han. There were no significant differences 
A

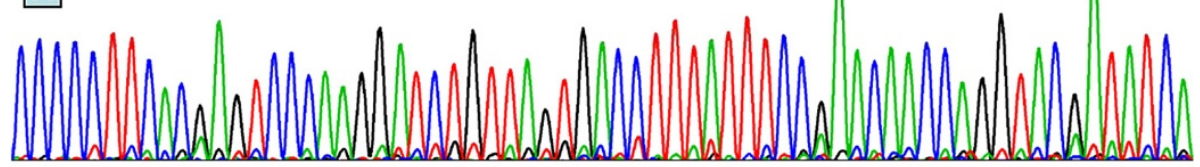

CCCCCTTCACGAGTCCCAAGGATCT GTTAGTGACCTTTATTCCGAACAACCAGGTACGATATCA B

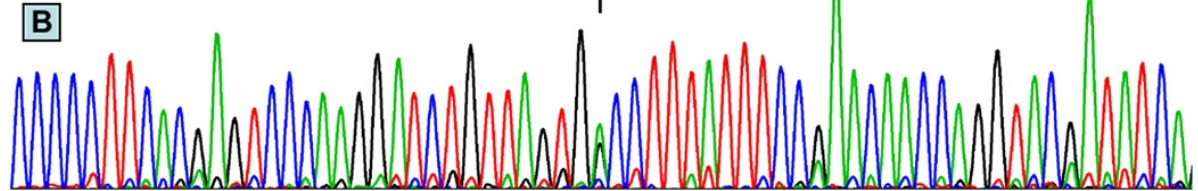

CCCССTTACGAG TCCCAAGG ATC TGTTAGT GGCCTTTATTTCCGAACAACCAGGTACGATATCA C

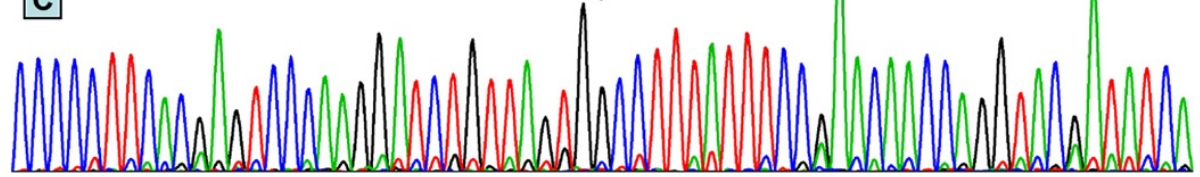

Figure 3 A part of the nucleotide sequence of rs3757354 SNP. (A) AA genotype; (B) GA genotype; (C) GG genotype.

in TG levels and the ratio of ApoAI to ApoB between the two ethnic groups. It is well known that dyslipidemia is the result of a combination of genetic and environmental factors [6-9]. LDL-C, HDL-C and TG concentrations are strongly influenced by the genetic constitution of each individual. Bai $\mathrm{Ku}$ Yao is a special and isolated subgroup of the Yao minority in China. Strict intraethnic marriages have been performed in this population from time immemorial. Therefore, we believed that the genetic background and some lipid metabolism-related gene polymorphisms in this population may be different from those in Han nationality.
In the present study, we showed that the frequency $G$ allele of rs3757354 SNP was lower in Bai Ku Yao than in Han. The frequencies of AA, GA and GG genotypes were also different between the two ethnic groups. There were no significant differences in the genotypic and allelic frequencies between males and females in both ethnic groups. These results indicated that the prevalence of the $\mathrm{G}$ allele variant of the rs3757354 SNP may have a racial/ethnic specificity.

The potential relationship between the MYLIP SNPs and plasma or serum lipid levels in humans has been evaluated in several previous GWAS. However, previous

Table 2 The genotypic and allelic frequencies of rs3757354 SNP in the Bai Ku Yao and Han populations [n (\%)]

\begin{tabular}{|c|c|c|c|c|c|c|}
\hline \multirow[t]{2}{*}{ Group } & \multirow[t]{2}{*}{$\mathbf{n}$} & \multicolumn{3}{|l|}{ Genotype } & \multicolumn{2}{|l|}{ Allele } \\
\hline & & $A A$ & $\mathrm{GA}$ & GG & G & $\mathbf{T}$ \\
\hline Bai Ku Yao & 627 & $160(25.52)$ & $308(49.12)$ & $159(25.36)$ & $628(50.08)$ & $626(49.92)$ \\
\hline Han & 614 & $122(19.87)$ & $293(47.72)$ & $199(32.41)$ & $537(43.73)$ & $691(56.27)$ \\
\hline$x^{2}$ & - & 9.829 & & & 10.045 & \\
\hline $\bar{P}$ & - & 0.007 & & & 0.002 & \\
\hline \multicolumn{7}{|l|}{ Bai Ku Yao } \\
\hline Male & 303 & $75(24.75)$ & $161(53.14)$ & $67(22.11)$ & $311(51.32)$ & $295(48.68)$ \\
\hline Female & 324 & $85(26.23)$ & $147(45.37)$ & $92(28.40)$ & 317 (48.92) & 331 (51.08) \\
\hline$x^{2}$ & - & 4.494 & & & 0.722 & \\
\hline$P$ & - & 0.106 & & & 0.397 & \\
\hline \multicolumn{7}{|l|}{$\operatorname{Han}$} \\
\hline Male & 294 & $61(20.75)$ & $142(48.30)$ & $91(30.95)$ & $264(44.90)$ & $324(55.10)$ \\
\hline Female & 320 & $61(19.06)$ & $151(47.19)$ & 108 (33.75) & $273(42.66)$ & $367(57.34)$ \\
\hline$\overline{x^{2}}$ & - & 0.629 & & & 0.626 & \\
\hline $\bar{P}$ & - & 0.730 & & & 0.454 & \\
\hline
\end{tabular}


Table 3 The genotypes of rs3757354 SNP and serum lipid levels in the Bai Ku Yao and Han populations

\begin{tabular}{|c|c|c|c|c|c|c|c|c|}
\hline Genotype & $\mathbf{n}$ & $\mathrm{TC}(\mathrm{mmol} / \mathrm{L})$ & TG (mmol/L) & HDL-C (mmol/L) & LDL-C (mmol/L) & ApoAl (g/L) & ApoB (g/L) & ApoAl/ ApoB \\
\hline \multicolumn{9}{|l|}{ Bai Ku Yao } \\
\hline $\mathrm{AA}$ & 160 & $4.38 \pm 1.16$ & $1.06(0.66)$ & $1.67 \pm 0.47$ & $2.58 \pm 0.97$ & $1.31 \pm 0.35$ & $0.84 \pm 0.24$ & $1.72 \pm 0.88$ \\
\hline $\mathrm{GA}$ & 308 & $4.36 \pm 0.87$ & $1.00(0.76)$ & $1.68 \pm 0.38$ & $2.55 \pm 0.70$ & $1.33 \pm 0.30$ & $0.85 \pm 0.23$ & $1.70 \pm 0.77$ \\
\hline$\overline{G G}$ & 159 & $4.42 \pm 0.78$ & $0.96(0.57)$ & $1.76 \pm 0.45$ & $2.60 \pm 0.71$ & $1.36 \pm 0.34$ & $0.84 \pm 0.21$ & $1.77 \pm 0.79$ \\
\hline$F$ & - & 0.150 & 2.437 & 3.206 & 0.162 & 2.052 & 0.354 & 1.241 \\
\hline$P$ & - & 0.861 & 0.296 & 0.041 & 0.851 & 0.129 & 0.702 & 0.290 \\
\hline \multicolumn{9}{|l|}{ Han Chinese } \\
\hline $\mathrm{AA}$ & 122 & $4.97 \pm 1.01$ & $1.15(0.74)$ & $1.93 \pm 0.49$ & $2.70 \pm 0.81$ & $1.47 \pm 0.29$ & $0.91 \pm 0.21$ & $1.69 \pm 0.46$ \\
\hline $\mathrm{GA}$ & 293 & $4.72 \pm 1.05$ & $1.02(0.78)$ & $1.81 \pm 0.44$ & $2.66 \pm 0.81$ & $1.40 \pm 0.25$ & $0.90 \pm 0.24$ & $1.65 \pm 0.50$ \\
\hline$\overline{\mathrm{GG}}$ & 199 & $4.72 \pm 0.88$ & $1.02(0.58)$ & $1.92 \pm 0.52$ & $2.64 \pm 0.68$ & $1.43 \pm 0.29$ & $0.88 \pm 0.20$ & $1.70 \pm 0.58$ \\
\hline$F$ & & 4.635 & 2.494 & 3.871 & 0.644 & 3.394 & 1.070 & 0.347 \\
\hline$P$ & & 0.010 & 0.287 & 0.021 & 0.526 & 0.034 & 0.343 & 0.707 \\
\hline \multicolumn{9}{|c|}{ Bai Ku Yao/male } \\
\hline $\mathrm{AA}$ & 75 & $4.44 \pm 1.50$ & $1.17(0.82)$ & $1.72 \pm 0.55$ & $2.53 \pm 1.27$ & $1.37 \pm 0.40$ & $0.81 \pm 0.28$ & $1.93 \pm 1.17$ \\
\hline $\mathrm{GA}$ & 161 & $4.35 \pm 0.94$ & $1.11(0.96)$ & $1.71 \pm 0.42$ & $2.47 \pm 0.76$ & $1.38 \pm 0.34$ & $0.82 \pm 0.23$ & $1.86 \pm 0.94$ \\
\hline GG & 67 & $4.52 \pm 0.85$ & $1.11(0.74)$ & $1.81 \pm 0.52$ & $2.60 \pm 0.83$ & $1.45 \pm 0.41$ & $0.83 \pm 0.24$ & $1.97 \pm 1.05$ \\
\hline$F$ & - & 0.216 & 0.284 & 0.979 & 0.314 & 1.315 & 0.051 & 0.193 \\
\hline$P$ & - & 0.806 & 0.867 & 0.377 & 0.731 & 0.270 & 0.950 & 0.825 \\
\hline \multicolumn{9}{|c|}{ Bai Ku Yao/female } \\
\hline$\overline{\mathrm{AA}}$ & 85 & $4.33 \pm 0.76$ & $0.97(0.55)$ & $1.62 \pm 0.39$ & $2.62 \pm 0.59$ & $1.26 \pm 0.29$ & $0.86 \pm 0.21$ & $1.53 \pm 0.43$ \\
\hline $\mathrm{GA}$ & 147 & $4.37 \pm 0.79$ & $0.93(0.59)$ & $1.66 \pm 0.33$ & $2.64 \pm 0.62$ & $1.27 \pm 0.25$ & $0.88 \pm 0.23$ & $1.53 \pm 0.48$ \\
\hline$\overline{\mathrm{GG}}$ & 92 & $4.34 \pm 0.71$ & $0.85(0.47)$ & $1.73 \pm 0.39$ & $2.60 \pm 0.61$ & $1.30 \pm 0.26$ & $0.84 \pm 0.19$ & $1.62 \pm 0.48$ \\
\hline$F$ & & 0.016 & 3.755 & 1.833 & 0.144 & 0.734 & 0.508 & 1.125 \\
\hline$P$ & & 0.984 & 0.153 & 0.162 & 0.866 & 0.481 & 0.602 & 0.326 \\
\hline \multicolumn{9}{|l|}{ Han/male } \\
\hline $\mathrm{AA}$ & 61 & $4.90 \pm 0.91$ & $1.27(0.99)$ & $1.84 \pm 0.43$ & $2.62 \pm 0.72$ & $1.42 \pm 0.23$ & $0.90 \pm 0.22$ & $1.66 \pm 0.43$ \\
\hline $\mathrm{GA}$ & 142 & $4.74 \pm 1.04$ & $1.03(0.79)$ & $1.83 \pm 0.47$ & $2.65 \pm 0.81$ & $1.41 \pm 0.26$ & $0.89 \pm 0.23$ & $1.67 \pm 0.50$ \\
\hline GG & 91 & $4.66 \pm 0.90$ & $1.08(0.75)$ & $1.83 \pm 0.49$ & $2.66 \pm 0.72$ & $1.37 \pm 0.29$ & $0.89 \pm 0.22$ & $1.63 \pm 0.66$ \\
\hline$F$ & - & 1.247 & 4.060 & 0.058 & 0.093 & 0.925 & 0.157 & 0.276 \\
\hline P & - & 0.289 & 0.131 & 0.943 & 0.912 & 0.398 & 0.854 & 0.759 \\
\hline \multicolumn{9}{|l|}{ Han/female } \\
\hline$\overline{A A}$ & 61 & $5.03 \pm 1.10$ & $1.03(0.76)$ & $2.01 \pm 0.54$ & $2.78 \pm 0.89$ & $1.51 \pm 0.33$ & $0.92 \pm 0.21$ & $1.71 \pm 0.49$ \\
\hline $\mathrm{GA}$ & 151 & $4.70 \pm 1.06$ & $1.00(0.74)$ & $1.80 \pm 0.41$ & $2.66 \pm 0.80$ & $1.38 \pm 0.24$ & $0.91 \pm 0.26$ & $1.63 \pm 0.50$ \\
\hline GG & 108 & $4.76 \pm 0.86$ & $0.99(0.49)$ & $2.01 \pm 0.53$ & $2.62 \pm 0.66$ & $1.48 \pm 0.29$ & $0.88 \pm 0.18$ & $1.75 \pm 0.49$ \\
\hline$F$ & - & 4.063 & 0.039 & 6.623 & 2.290 & 5.796 & 1.109 & 1.342 \\
\hline$P$ & - & 0.018 & 0.981 & 0.002 & 0.103 & 0.003 & 0.331 & 0.263 \\
\hline
\end{tabular}

$T C$, total cholesterol; TG, triglyceride; $H D L-C$, high-density lipoprotein cholesterol; $L D L-C$, low-density lipoprotein cholesterol; $A p o A I$, apolipoprotein Al; $A p o B$, apolipoprotein B.

findings on the association of rs3757354 SNP with the changes in plasma lipid levels were inconsistent. MYLIP in GWAS has been shown significant associations with LDL-C concentrations in Europeans [15-17]. Jeemon et al. [49] identified several novel loci including rs3757354 SNP associated with LDL-C in the implications of discoveries from genome-wide association studies. Teslovich et al. [23], Waterworth et al. [25] and Weissglas-Volkov et al. [35] also demonstrated that rs3757354 SNP was genome-wide significant association with LDL-C. Furthermore, Banka et al. [37] and Kararigas et al. [38] found that MYLIP is a sex-specific element influencing contractile function. However, Santos et al. [36] showed MYLIP p.N342S polymorphism was not associated with lipid profiles in the Brazilian population. In the present study, we showed that the levels of HDL-C in Bai $\mathrm{Ku}$ Yao were different among the three genotypes, the $G$ allele carriers had higher 
Table 4 Correlation between the genotypes of rs3757354 SNP and serum lipid parameters in the Bai Ku Yao and Han populations

\begin{tabular}{|c|c|c|c|c|c|c|}
\hline Lipid parameter & Relative factor & $\begin{array}{l}\text { Unstandardized } \\
\text { coefficient }\end{array}$ & Std. error & $\begin{array}{l}\text { Standardized } \\
\text { coefficient }\end{array}$ & $t$ & $P$ \\
\hline \multicolumn{7}{|l|}{ Bai and Han } \\
\hline \multirow[t]{4}{*}{$\mathrm{TC}$} & Body mass index & 0.066 & 0.010 & 0.191 & 6.918 & 0.000 \\
\hline & Ethnic group & 0.367 & 0.053 & 0.187 & 6.985 & 0.000 \\
\hline & Age & 0.007 & 0.002 & 0.107 & 3.932 & 0.000 \\
\hline & Diastolic blood pressure & 0.010 & 0.003 & 0.104 & 3.706 & 0.000 \\
\hline \multirow[t]{5}{*}{ TG } & Body mass index & 0.064 & 0.011 & 0.163 & 5.699 & 0.000 \\
\hline & Gender & -0.244 & 0.067 & -0.110 & -3.660 & 0.000 \\
\hline & Genotype & -0.112 & 0.043 & -0.072 & -2.612 & 0.009 \\
\hline & Diastolic blood pressure & 0.007 & 0.003 & 0.063 & 2.192 & 0.028 \\
\hline & Alcohol consumption & 0.095 & 0.046 & 0.063 & 2.079 & 0.037 \\
\hline \multirow[t]{6}{*}{$\mathrm{HDL}-\mathrm{C}$} & Ethnic group & 0.184 & 0.025 & 0.200 & 7.276 & 0.000 \\
\hline & Alcohol consumption & 0.122 & 0.019 & 0.196 & 6.295 & 0.000 \\
\hline & Age & 0.004 & 0.001 & 0.131 & 4.811 & 0.000 \\
\hline & Body mass index & -0.017 & 0.004 & -0.103 & -3.766 & 0.000 \\
\hline & Cigarette smoking & -0.064 & 0.019 & -0.105 & -3.392 & 0.000 \\
\hline & Genotype & 0.038 & 0.017 & 0.060 & 2.192 & 0.028 \\
\hline \multirow[t]{4}{*}{$\underline{L D L-C}$} & Body mass index & 0.061 & 0.008 & 0.224 & 7.972 & 0.000 \\
\hline & Age & 0.006 & 0.001 & 0.112 & 4.058 & 0.000 \\
\hline & Alcohol consumption & -0.130 & 0.029 & -0.124 & -4.465 & 0.000 \\
\hline & Diastolic blood pressure & 0.006 & 0.002 & 0.082 & 2.834 & 0.004 \\
\hline \multirow[t]{3}{*}{ ApoAl } & Alcohol consumption & 0.087 & 0.011 & 0.213 & 7.795 & 0.000 \\
\hline & Ethnic group & 0.104 & 0.016 & 0.172 & 6.333 & 0.000 \\
\hline & Age & 0.003 & 0.001 & 0.168 & 6.195 & 0.000 \\
\hline \multirow[t]{5}{*}{ ApoB } & Body mass index & 0.019 & 0.002 & 0.233 & 8.445 & 0.000 \\
\hline & Age & 0.002 & 0.000 & 0.124 & 4.547 & 0.000 \\
\hline & Diastolic blood pressure & 0.003 & 0.001 & 0.126 & 4.432 & 0.000 \\
\hline & Ethnic group & 0.045 & 0.012 & 0.098 & 3.620 & 0.000 \\
\hline & Alcohol consumption & -0.020 & 0.009 & -0.065 & -2.360 & 0.018 \\
\hline \multirow[t]{3}{*}{ ApoAl/ApoB } & Alcohol consumption & 0.186 & 0.026 & 0.202 & 7.210 & 0.000 \\
\hline & Body mass index & -0.036 & 0.007 & -0.153 & -5.376 & 0.000 \\
\hline & Diastolic blood pressure & -0.004 & 0.002 & -0.068 & -2.382 & 0.017 \\
\hline \multicolumn{7}{|l|}{ Bai Ku Yao } \\
\hline \multirow[t]{2}{*}{$\mathrm{TC}$} & Body mass index & 0.085 & 0.015 & 0.218 & 5.597 & 0.000 \\
\hline & Age & 0.009 & 0.003 & 0.132 & 3.392 & 0.000 \\
\hline \multirow[t]{5}{*}{ TG } & Alcohol consumption & 0.217 & 0.075 & 0.142 & 2.888 & 0.004 \\
\hline & Body mass index & 0.076 & 0.019 & 0.157 & 4.055 & 0.000 \\
\hline & Gender & -0.507 & 0.129 & -0.219 & -3.922 & 0.000 \\
\hline & Cigarette smoking & -0.201 & 0.079 & -0.138 & -2.552 & 0.010 \\
\hline & Genotype & -0.132 & 0.062 & -0.081 & -2.118 & 0.034 \\
\hline \multirow[t]{3}{*}{$\mathrm{HDL}-\mathrm{C}$} & Alcohol consumption & 0.092 & 0.022 & 0.165 & 4.200 & 0.000 \\
\hline & Age & 0.003 & 0.001 & 0.111 & 2.837 & 0.004 \\
\hline & Genotype & 0.051 & 0.023 & 0.087 & 2.212 & 0.027 \\
\hline \multirow[t]{4}{*}{ LDL-C } & Body mass index & 0.071 & 0.013 & 0.219 & 5.616 & 0.000 \\
\hline & Age & 0.007 & 0.002 & 0.120 & 3.023 & 0.002 \\
\hline & Alcohol consumption & -0.144 & 0.041 & -0.140 & -3.548 & 0.000 \\
\hline & Diastolic blood pressure & 0.007 & 0.003 & 0.092 & 2.268 & 0.023 \\
\hline
\end{tabular}


Table 4 Correlation between the genotypes of rs3757354 SNP and serum lipid parameters in the Bai Ku Yao and Han populations (Continued)

\begin{tabular}{|c|c|c|c|c|c|c|}
\hline ApoAl & Alcohol consumption & 0.119 & 0.016 & 0.279 & 7.289 & 0.000 \\
\hline & Age & 0.002 & 0.001 & 0.101 & 2.649 & 0.008 \\
\hline \multirow[t]{4}{*}{ ApoB } & Body mass index & 0.023 & 0.004 & 0.242 & 6.249 & 0.000 \\
\hline & Age & 0.002 & 0.001 & 0.138 & 3.501 & 0.000 \\
\hline & Alcohol consumption & -0.041 & 0.012 & -0.136 & -3.491 & 0.000 \\
\hline & Diastolic blood pressure & 0.003 & 0.001 & 0.108 & 2.685 & 0.007 \\
\hline \multirow[t]{2}{*}{ ApoAl/ApoB } & Alcohol consumption & 0.288 & 0.041 & 0.271 & 7.071 & 0.000 \\
\hline & Body mass index & -0.053 & 0.013 & -0.158 & -4.133 & 0.000 \\
\hline \multicolumn{7}{|l|}{ Han } \\
\hline \multirow[t]{4}{*}{ TC } & Body mass index & 0.062 & 0.012 & 0.202 & 5.021 & 0.000 \\
\hline & Systolic blood pressure & 0.007 & 0.002 & 0.122 & 2.969 & 0.003 \\
\hline & Age & 0.006 & 0.003 & 0.101 & 2.550 & 0.011 \\
\hline & Genotype & -0.118 & 0.054 & -0.085 & -2.186 & 0.029 \\
\hline \multirow[t]{3}{*}{ TG } & Body mass index & 0.053 & 0.014 & 0.162 & 3.913 & 0.000 \\
\hline & Diastolic blood pressure & 0.010 & 0.004 & 0.105 & 2.525 & 0.011 \\
\hline & Cigarette smoking & 0.153 & 0.060 & 0.100 & 2.522 & 0.011 \\
\hline \multirow[t]{5}{*}{ HDL-C } & Age & 0.005 & 0.001 & 0.160 & 4.088 & 0.000 \\
\hline & Alcohol consumption & 0.133 & 0.029 & 0.196 & 4.655 & 0.000 \\
\hline & Cigarette smoking & -0.103 & 0.029 & -0.151 & -3.546 & 0.000 \\
\hline & Body mass index & -0.018 & 0.006 & -0.125 & -3.194 & 0.001 \\
\hline & Gender & 0.084 & 0.039 & 0.087 & 2.166 & 0.030 \\
\hline \multirow[t]{4}{*}{ LDL-C } & Body mass index & 0.062 & 0.009 & 0.263 & 6.773 & 0.000 \\
\hline & Age & 0.006 & 0.002 & 0.117 & 3.015 & 0.002 \\
\hline & Alcohol consumption & -0.148 & 0.045 & -0.136 & -3.264 & 0.001 \\
\hline & Cigarette smoking & 0.140 & 0.045 & 0.127 & 3.073 & 0.002 \\
\hline \multirow[t]{3}{*}{ ApoAl } & Age & 0.004 & 0.001 & 0.252 & 6.524 & 0.000 \\
\hline & Alcohol consumption & 0.057 & 0.015 & 0.148 & 3.774 & 0.000 \\
\hline & Gender & 0.059 & 0.021 & 0.108 & 2.763 & 0.005 \\
\hline \multirow[t]{3}{*}{ ApoB } & Body mass index & 0.017 & 0.003 & 0.240 & 6.115 & 0.000 \\
\hline & Systolic blood pressure & 0.002 & 0.001 & 0.153 & 3.802 & 0.000 \\
\hline & Age & 0.002 & 0.001 & 0.106 & 2.705 & 0.007 \\
\hline ApoAl/ApoB & Body mass index & -0.031 & 0.006 & -0.191 & -4.823 & 0.000 \\
\hline
\end{tabular}

TC, total cholesterol; $T G$, triglyceride; $H D L-C$, high-density lipoprotein cholesterol; $L D L-C$, low-density lipoprotein cholesterol; $A p o A l$, apolipoprotein $A l ; A p o B$, apolipoprotein B.

serum HDL-C levels than the $\mathrm{G}$ allele noncarriers. The levels of TC, HDL-C and ApoAI in Han were also different among the three genotypes, the subjects with GA genotype had lower serum TC, HDL-C and ApoAI levels than the subjects with AA genotype. These findings were restricted to females but not males. Multiple linear regression analysis also showed that serum TG and HDL-C levels in Bai Ku Yao were correlated with the genotypes of rs3757354 SNP, whereas the levels of TC in Han, and TC, LDL-C in Han females were associated with the genotypes. These findings suggest that the association of MYLIP rs3757354 SNP and serum lipid levels is different between the two ethnic groups.
There may be a sex-specific association of rs3757354 SNP and serum lipid parameters in Han population.

It is well known that environmental factors such as dietary patterns, lifestyle, obesity, physical inactivity, and hypertension are all strongly related with serum lipid levels [6,7]. Furthermore, exposure to different lifestyle and environmental factors in our population resident in Guangxi may further modify the effect of genetic variation on serum lipid phenotypes. Multivariate linear regression analysis showed that age, sex, BMI, alcohol consumption, cigarette smoking, and blood pressure were involved in determining serum lipid parameters. These findings suggest that the environmental factors 
Table 5 Relative factors for serum lipid parameters between males and females in both ethnic groups

\begin{tabular}{|c|c|c|c|c|c|c|}
\hline Lipid parameter & Relative factor & $\begin{array}{l}\text { Unstandardized } \\
\text { coefficient }\end{array}$ & Std. error & $\begin{array}{l}\text { Standardized } \\
\text { coefficient }\end{array}$ & $t$ & $P$ \\
\hline \multicolumn{7}{|l|}{ Bai Ku Yao/male } \\
\hline$\overline{\mathrm{TC}}$ & Body mass index & 0.136 & 0.027 & 0.277 & 5.004 & 0.000 \\
\hline$\overline{\mathrm{TG}}$ & Body mass index & 0.137 & 0.038 & 0.204 & 3.611 & 0.000 \\
\hline \multirow[t]{3}{*}{$\mathrm{HDL}-\mathrm{C}$} & Alcohol consumption & 0.132 & 0.036 & 0.207 & 3.681 & 0.000 \\
\hline & Age & 0.005 & 0.002 & 0.159 & 2.836 & 0.004 \\
\hline & Body mass index & -0.028 & 0.012 & -0.131 & -2.364 & 0.018 \\
\hline $\mathrm{LDL}-\mathrm{C}$ & Body mass index & 0.113 & 0.023 & 0.271 & 4.877 & 0.000 \\
\hline \multirow[t]{2}{*}{ ApoAl } & Alcohol consumption & 0.134 & 0.028 & 0.271 & 4.883 & 0.000 \\
\hline & Age & 0.003 & 0.001 & 0.126 & 2.273 & 0.023 \\
\hline \multirow[t]{2}{*}{ ApoB } & Body mass index & 0.031 & 0.006 & 0.279 & 5.024 & 0.000 \\
\hline & Diastolic blood pressure & 0.003 & 0.001 & 0.113 & 2.028 & 0.043 \\
\hline \multirow[t]{2}{*}{ ApoAl/ApoB } & Alcohol consumption & 0.290 & 0.077 & 0.212 & 3.790 & 0.000 \\
\hline & Body mass index & -0.090 & 0.026 & -0.196 & -3.513 & 0.000 \\
\hline \multicolumn{7}{|l|}{ Bai Ku Yao/female } \\
\hline \multirow[t]{3}{*}{$\mathrm{TC}$} & Age & 0.011 & 0.003 & 0.192 & 3.511 & 0.000 \\
\hline & Body mass index & 0.059 & 0.017 & 0.196 & 3.528 & 0.000 \\
\hline & Alcohol consumption & -0.205 & 0.090 & -0.126 & -2.275 & 0.023 \\
\hline \multirow[t]{3}{*}{$\mathrm{TG}$} & Alcohol consumption & 0.207 & 0.075 & 0.151 & 2.742 & 0.006 \\
\hline & Body mass index & 0.039 & 0.014 & 0.156 & 2.833 & 0.004 \\
\hline & Genotype & -0.108 & 0.046 & -0.126 & -2.337 & 0.020 \\
\hline \multirow[t]{3}{*}{$\mathrm{LDL}-\mathrm{C}$} & Age & 0.009 & 0.002 & 0.212 & 3.917 & 0.000 \\
\hline & Body mass index & 0.050 & 0.013 & 0.211 & 3.823 & 0.000 \\
\hline & Alcohol consumption & -0.222 & 0.072 & -0.169 & -3.092 & 0.002 \\
\hline \multirow[t]{3}{*}{ ApoB } & Diastolic blood pressure & 0.003 & 0.001 & 0.113 & 2.019 & 0.044 \\
\hline & Body mass index & 0.015 & 0.005 & 0.179 & 3.259 & 0.001 \\
\hline & Age & 0.003 & 0.001 & 0.166 & 2.957 & 0.003 \\
\hline \multirow[t]{2}{*}{ ApoAl/ApoB } & Diastolic blood pressure & -0.009 & 0.003 & -0.185 & -3.373 & 0.000 \\
\hline & Alcohol consumption & 0.113 & 0.055 & 0.112 & 2.052 & 0.040 \\
\hline \multicolumn{7}{|l|}{ Han/male } \\
\hline \multirow[t]{3}{*}{$\mathrm{TC}$} & Diastolic blood pressure & 0.012 & 0.005 & 0.148 & 2.471 & 0.014 \\
\hline & Body mass index & 0.037 & 0.017 & 0.128 & 2.139 & 0.033 \\
\hline & Age & 0.007 & 0.004 & 0.122 & 2.137 & 0.033 \\
\hline \multirow[t]{2}{*}{$\overline{\mathrm{TG}}$} & Diastolic blood pressure & 0.019 & 0.006 & 0.179 & 2.999 & 0.002 \\
\hline & Body mass index & 0.054 & 0.022 & 0.150 & 2.510 & 0.012 \\
\hline \multirow[t]{4}{*}{$\mathrm{HDL}-\mathrm{C}$} & Alcohol consumption & 0.186 & 0.036 & 0.300 & 5.166 & 0.000 \\
\hline & Age & 0.004 & 0.002 & 0.145 & 2.610 & 0.009 \\
\hline & Cigarette smoking & -0.089 & 0.033 & -0.157 & -2.736 & 0.006 \\
\hline & Body mass index & -0.018 & 0.008 & -0.131 & -2.366 & 0.018 \\
\hline \multirow[t]{3}{*}{$\mathrm{LDL}-\mathrm{C}$} & Body mass index & 0.050 & 0.013 & 0.220 & 3.875 & 0.000 \\
\hline & Cigarette smoking & 0.177 & 0.055 & 0.189 & 3.212 & 0.001 \\
\hline & Alcohol consumption & -0.139 & 0.060 & -0.136 & -2.300 & 0.022 \\
\hline \multirow[t]{2}{*}{ ApoAl } & Age & 0.004 & 0.001 & 0.265 & 4.850 & 0.000 \\
\hline & Alcohol consumption & 0.087 & 0.019 & 0.246 & 4.495 & 0.000 \\
\hline \multirow[t]{2}{*}{ ApoB } & Body mass index & 0.014 & 0.004 & 0.215 & 3.822 & 0.000 \\
\hline & Age & 0.002 & 0.001 & 0.168 & 2.976 & 0.003 \\
\hline
\end{tabular}


Table 5 Relative factors for serum lipid parameters between males and females in both ethnic groups (Continued)

\begin{tabular}{|c|c|c|c|c|c|c|}
\hline ApoAl/ApoB & Alcohol consumption & 0.151 & 0.041 & 0.209 & 3.668 & 0.000 \\
\hline & Body mass index & -0.026 & 0.009 & -0.162 & -2.851 & 0.004 \\
\hline \multicolumn{7}{|l|}{ Han/female } \\
\hline \multirow[t]{3}{*}{$\mathrm{TC}$} & Body mass index & 0.086 & 0.018 & 0.268 & 4.829 & 0.000 \\
\hline & Systolic blood pressure & 0.008 & 0.003 & 0.144 & 2.618 & 0.009 \\
\hline & Genotype & -0.153 & 0.076 & -0.108 & -2.020 & 0.044 \\
\hline \multirow[t]{2}{*}{$\mathrm{TG}$} & Cigarette smoking & 0.335 & 0.095 & 0.192 & 3.538 & 0.000 \\
\hline & Body mass index & 0.048 & 0.015 & 0.171 & 3.160 & 0.001 \\
\hline \multirow[t]{2}{*}{$\mathrm{HDL}-\mathrm{C}$} & Age & 0.005 & 0.002 & 0.169 & 3.028 & 0.002 \\
\hline & Body mass index & -0.017 & 0.009 & -0.111 & -1.992 & 0.047 \\
\hline \multirow[t]{3}{*}{ LDL-C } & Body mass index & 0.078 & 0.013 & 0.318 & 5.922 & 0.000 \\
\hline & Genotype & -0.124 & 0.058 & -0.114 & -2.145 & 0.032 \\
\hline & Age & 0.006 & 0.003 & 0.109 & 2.060 & 0.040 \\
\hline$\overline{A p o A l}$ & Age & 0.004 & 0.001 & 0.234 & 4.284 & 0.000 \\
\hline \multirow[t]{3}{*}{ ApoB } & Body mass index & 0.020 & 0.004 & 0.279 & 5.308 & 0.000 \\
\hline & Systolic blood pressure & 0.003 & 0.001 & 0.225 & 4.285 & 0.000 \\
\hline & Alcohol consumption & 0.045 & 0.018 & 0.128 & 2.503 & 0.012 \\
\hline \multirow[t]{2}{*}{ ApoAl/ApoB } & Body mass index & -0.037 & 0.009 & -0.234 & -4.325 & 0.000 \\
\hline & Cigarette smoking & -0.119 & 0.053 & -0.122 & -2.254 & 0.024 \\
\hline
\end{tabular}

$T C$, total cholesterol; TG, triglyceride; $H D L-C$, high-density lipoprotein cholesterol; $L D L-C$, low-density lipoprotein cholesterol; $A p o A l$, apolipoprotein $A l ; A p o B$, apolipoprotein B.

also play an important role in determining serum lipid levels in our study populations. Differences in serum lipid levels between the two ethnic groups could be related to factors such as differences in the genetic background, dietary patterns and lifestyle factors and their interactions. Although Bai Ku Yao and Han reside in the same region, there were significant differences in their diet and lifestyle. Corn was the staple food and rice, soy, buck wheat, sweet potato, and pumpkin products were the subsidiary foods in Bai Ku Yao. Approximately 90\% of the beverages were corn wine and rum. The alcohol content is about $15 \%(\mathrm{v} / \mathrm{v})$. They are also accustomed to drink Hempseed soup. In contrast, rice was the staple food and corn, broomcorn, potato, and taro products were the subsidiary foods in Han. About $90 \%$ of the beverage was rice wine. The content of alcohol is about $30 \%$ $(\mathrm{v} / \mathrm{v})$. The staple and subsidiary foods are more favorable for serum lipid profiles in Bai Ku Yao than in Han. Corn contains abundant dietary fiber and plant protein [50]. Dietary fiber can decrease serum TC levels [51]. Plant protein can promote the transportation and excretion of free cholesterol. Dietary soy protein has well documented beneficial effects on serum lipid concentrations $[52,53]$.

\section{Conclusion}

The present study shows that there were significant differences in the genotypic and allelic frequencies of MYLIP rs3757354 SNP between Bai Ku Yao and Han populations. The levels of HDL-C in Bai $\mathrm{Ku}$ Yao were different among the genotypes, the $\mathrm{G}$ allele carriers had higher serum HDL-C levels than the $G$ allele noncarriers. The levels TC, HDL-C and ApoAI in Han were different among the genotypes, the participants with GA genotype had lower serum TC, HDL-C and ApoAI levels than the participants with AA genotype. The levels of TG and HDL-C in Bai Ku Yao were correlated with the genotypes, whereas the levels of TC in Han, and TC, LDL-C in Han females were associated with the genotypes. These results suggest that the association of MYLIP rs3757354 SNP and serum lipid levels is different between the two ethnic groups. There may be a sexspecific association of rs3757354 SNP and serum lipid parameters in the Han population.

\section{Competing interests}

The authors declare that they have no competing interests.

\section{Authors' contributions}

TTY participated in the design, undertook genotyping, performed the statistical analyses, and drafted the manuscript. RXY conceived the study, participated in the design, carried out the epidemiological survey, collected the samples, and helped to draft the manuscript. QL, PH, XNZ, KKH, DFW and LHHA carried out the epidemiological survey and collaborated to the genotyping. All authors read and approved the final manuscript.

Acknowledgments

This study was supported by the National Natural Science Foundation of China (No: 30660061)

Received: 10 September 2012 Accepted: 27 October 2012

Published: 29 October 2012 


\section{References}

1. Austin MA, Hokanson JE, Edwards KL: Hypertriglyceridemia as acardiovascular risk factor. Am J Cardiol 1998, 81:7B-12B.

2. Castelli WP, Anderson K, Wilson PW, Levy D: Lipids and risk of coronary heart disease. The Framingham Study. Ann Epidemiol 1992, 2:23-28.

3. Brunzell JD, Sniderman AD, Albers JJ, Kwiterovich PO Jr: Apoproteins B and A-I and coronary artery disease in humans. Arteriosclerosis 1984, 4:79-83.

4. Holewijn S, den Heijer M, Swinkels DW, Stalenhoef AFH, de Graaf J: Apolipoprotein B, non-HDL cholesterol and LDL cholesterol for identifying individuals at increased cardiovascular risk. J Intern Med 2010, 268:567-577.

5. Achari V, Thakur AK: Association of major modifiable risk factors among patients with coronary a rtery disease -a retrospective analysis. $J$ Assoc Physicians India 2004, 52:103-108.

6. Ruixing $Y$, Yuming $C$, Shangling P, Fengping $H$, Tangwei $L$, Dezhai $Y$, Jinzhen W, Limei $Y$, Weixiong $L$, Rongshan $L$, Jiandong $H$ : Effects of demographic, dietary and other lifestyle factors on the prevalence of hyperlipidemia in Guangxi Hei Yi Zhuang and Han populations. Eur $J$ Cardiovasc Prev Rehabil 2006, 13:977-984.

7. Ruixing Y, Qiming F, Dezhai Y, Shuquan L, Weixiong L, Shangling P, Hai W, Yongzhong Y, Feng H, Shuming Q: Comparison of demography, diet, lifestyle, and serum lipid levels between the Guangxi Bai Ku Yao and Han populations. J Lipid Res 2007, 48:2673-2681.

8. Ruixing $Y$, Jinzhen W, Yaoheng H, Jing T, Hai W, Muyan L, Yiyang L, Dongmei F, Hanjun Y, Yuming C: Associations of diet and lifestyle with hyperlipidemia for middle-aged and elderly persons among the Guangxi Bai Ku Yao and Han populations. J Am Diet Assoc 2008, 108:970-976.

9. Ruixing Y, Jinzhen W, Weixiong L, Yuming C, Dezhai Y, Shangling P: The environmental and genetic evidence for the association of hyperlipidemia and hypertension. J Hypertens 2009, 27:251-258.

10. Pilia G, Chen WM, Scuteri A, Orrú M, Albai G, Dei M, Lai S, Usala G, Lai M, Loi P, Mameli C, Vacca L, Deiana M, Olla N, Masala M, Cao A, Najjar SS, Terracciano A, Nedorezov T, Sharov A, Zonderman AB, Abecasis GR, Costa P, Lakatta E, Schlessinger D: Heritability of cardiovascular and personality traits in 6,148 Sardinians. PLoS Genet 2006, 2:e132.

11. Pollin TI, Hsueh WC, Steinle NI, Snitker S, Shuldiner AR, Mitchell BD: A genome-wide scan of serum lipid levels in the Old Order Amish. Atherosclerosis 2004, 173:89-96.

12. Yang $Q$, Lai CQ, Parnell L, Cupples LA, Adiconis X, Zhu Y, Wilson PW Housman DE, Shearman AM, D'Agostino RB, Ordovas JM: Genome-wide linkage analyses and candidate gene fine mapping for HDL3 cholesterol: the Framingham Study. J Lipid Res 2005, 46:1416-1425.

13. Harrap SB, Wong ZY, Scurrah K, Lamantia A: Genome-wide linkage analysis of population variation in high-density lipoprotein cholesterol. Hum Genet 2006, 119:541-546.

14. Diabetes Genetics Initiative of Broad Institute of Harvard and MIT, Lund University, and Novartis Institutes of BioMedical Research, Saxena R, Voight BF, Lyssenko V, Burtt NP, de Bakker PI, Chen H, Roix JJ, Kathiresan S, Hirschhorn JN, Daly MJ, Hughes TE, Groop L, Altshuler D, Almgren P, Florez JC, Meyer J, Ardlie K, Bengtsson Boström K, Isomaa B, Lettre G, Lindblad U, Lyon HN, Melander O, Newton-Cheh C, Nilsson P, Orho-Melander M, Råstam L, Speliotes EK, Taskinen MR, et al: Genome-wide association analysis identifies loci for type 2 diabetes and triglyceride levels. Science 2007, 316:1331-1336

15. Kathiresan S, Melander O, Guiducci C, Surti A, Burtt NP, Rieder MJ, Cooper GM, Roos C, Voight BF, Havulinna AS, Wahlstrand B, Hedner T, Corella D, Tai ES, Ordovas JM, Berglund G, Vartiainen E, Jousilahti P, Hedblad B, Taskinen MR, Newton-Cheh C, Salomaa V, Peltonen L, Groop L, Altshuler DM, OrhoMelander M: Six new loci associated with blood low-density lipoprotein cholesterol, high-density lipoprotein cholesterol or triglycerides in humans. Nat Genet 2008, 40:189-197.

16. Sandhu MS, Waterworth DM, Debenham SL, Wheeler E, Papadakis K, Zhao JH, Song K, Yuan X, Johnson T, Ashford S, Inouye M, Luben R, Sims M, Hadley D, McArdle W, Barter P, Kesäniemi YA, Mahley RW, McPherson R, Grundy SM, Wellcome Trust Case Control Consortium, Bingham SA, Khaw $K T$, Loos RJ, Waeber G, Barroso I, Strachan DP, Deloukas P, Vollenweider P, Wareham NJ, Mooser V: LDL-cholesterol concentrations: a genome-wide association study. Lancet 2008, 371:483-491.

17. Willer CJ, Sanna S, Jackson AU, Scuteri A, Bonnycastle LL, Clarke R, Heath SC, Timpson NJ, Najjar SS, Stringham HM, Strait J, Duren WL, Maschio A, Busonero F, Mulas A, Albai G, Swift AJ, Morken MA, Narisu N, Bennett D,
Parish S, Shen H, Galan P, Meneton P, Hercberg S, Zelenika D, Chen WM, L Y, Scott LJ, Scheet PA, et al: Newly identified loci that influence lipid concentrations and risk of coronary artery disease. Nat Genet 2008, 40:161-169.

18. Johansen CT, Wang J, Lanktree MB, Cao H, Mclntyre AD, Ban MR, Martins RA, Kennedy BA, Hassell RG, Visser ME, Schwartz SM, Voight BF, Elosua R, Salomaa V, O'Donnell CJ, Dallinga-Thie GM, Anand SS, Yusuf S, Huff MW, Kathiresan S, Hegele RA: Excess of rare variants in genes identified by genome-wide association study of hypertriglyceridemia. Nat Genet 2010, 42:684-687.

19. Dumitrescu L, Carty CL, Taylor K, Schumacher FR, Hindorff LA, Ambite JL, Anderson G, Best LG, Brown-Gentry K, Bưžková P, Carlson CS, Cochran B, Cole SA, Devereux RB, Duggan D, Eaton CB, Fornage M, Franceschini N, Haessler J, Howard BV, Johnson KC, Laston S, Kolonel LN, Lee ET, MacCluer JW, Manolio TA, Pendergrass SA, Quibrera M, Shohet RV, Wilkens LR, et al: Genetic determinants of lipid traits in diverse populations from the population architecture using genomics and epidemiology (PAGE) study. PLoS Genet 2011, 7:e1002138.

20. Zhang Z, Tao L, Chen Z, Zhou D, Kan M, Zhang D, Li C, He L, Liu Y: Association of genetic Loci with blood lipids in the Chinese population. PLoS One 2011, 6:e27305.

21. Nakayama K, Bayasgalan T, Yamanaka K, Kumada M, Gotoh T, Utsumi N, Yanagisawa Y, Okayama M, Kajii E, Ishibashi S, Iwamoto S, Jichi Community Genetics Team (JCOG): Large scale replication analysis of loci associated with lipid concentrations in a Japanese population. J Med Genet 2009, 46:370-374.

22. Kathiresan $\mathrm{S}$, Melander $\mathrm{O}$, Anevski D, Guiducci C, Burtt NP, Roos $\mathrm{C}$, Hirschhorn JN, Berglund G, Hedblad B, Groop L, Altshuler DM, NewtonCheh C, Orho-Melander M: Polymorphisms associated with cholesterol and risk of cardiovascular events. N Engl J Med 2008, 358:1240-1249.

23. Teslovich TM, Musunuru K, Smith AV, Edmondson AC, Stylianou IM, Koseki M, Pirruccello JP, Ripatti S, Chasman DI, Willer CJ, Johansen CT, Fouchier SW, Isaacs A, Peloso GM, Barbalic M, Ricketts SL, Bis JC, Aulchenko YS, Thorleifsson G, Feitosa MF, Chambers J, Orho-Melander M, Melander O, Johnson T, Li X, Guo X, Li M, Shin Cho Y, Jin Go M, Jin Kim Y, et al: Biological, clinical and population relevance of 95 loci for blood lipids. Nature 2010, 466:707-713.

24. Chasman DI, Paré G, Mora S, Hopewell JC, Peloso G, Clarke R, Cupples LA, Hamsten A, Kathiresan S, Mälarstig A, Ordovas JM, Ripatti S, Parker AN, Miletich JP, Ridker PM: Forty-three loci associated with plasma lipoprotein size, concentration, and cholesterol content in genome-wide analysis. PLoS Genet 2009, 5:e1000730.

25. Waterworth DM, Ricketts SL, Song K, Chen L, Zhao JH, Ripatti S, Aulchenko YS, Zhang W, Yuan X, Lim N, Luan J, Ashford S, Wheeler E, Young EH, Hadley D, Thompson JR, Braund PS, Johnson T, Struchalin M, Surakka I, Luben R, Khaw KT, Rodwell SA, Loos RJ, Boekholdt SM, Inouye M, Deloukas P, Elliott P, Schlessinger D, Sanna S, et al: Genetic variants influencing circulating lipid levels and risk of coronary artery disease. Arterioscler Thromb Vasc Biol 2010, 30:2264-2276.

26. Dong B, Wu M, Cao A, Li H, Liu J: Suppression of Idol expression is an additional mechanism underlying statin-induced up-regulation of hepatic LDL receptor expression. Int J Mol Med 2011, 27:103-110.

27. Do HT, Tselykh TV, Mäkelä J, Ho TH, Olkkonen VM, Bornhauser BC, Korhonen L, Zelcer N, Lindholm D: Fibroblast growth factor-21 (FGF21) regulates low-density lipoprotein receptor (LDLR) levels in cells via the E3ubiquitin ligase Mylip/ldol and the Canopy2 (Cnpy2)/Mylip-interacting saposin-like protein (Msap). J Biol Chem 2012, 287:12602-12611.

28. Chasman DI, Giulianini F, MacFadyen J, Barratt BJ, Nyberg F, Ridker PM: Genetic determinants of statin-induced low-density lipoprotein cholesterol reduction: the Justification for the Use of Statins in Prevention: an Intervention Trial Evaluating Rosuvastatin (JUPITER) trial. Circ Cardiovasc Genet 2012, 5:257-264.

29. Sorrentino V, Scheer L, Santos A, Reits E, Bleijlevens B, Zelcer N: Distinct functional domains contribute to degradation of the low density lipoprotein receptor (LDLR) by the E3 ubiquitin ligase inducible Degrader of the LDLR (IDOL). J Biol Chem 2011, 286:30190-30199.

30. Zhang L, Fairall L, Goult BT, Calkin AC, Hong C, Millard CJ, Tontonoz P, Schwabe JW: The IDOL-UBE2D complex mediates sterol-dependent degradation of the LDL receptor. Genes 2011, 25:1262-1274.

31. Sawamura T: New Idol for cholesterol reduction? Clin Chem 2009, 55:2082-2084 
32. Hong C, Duit S, Jalonen $P$, Out R, Scheer L, Sorrentino V, Boyadjian R, Rodenburg KW, Foley E, Korhonen L, Lindholm D, Nimpf J, van Berkel TJ, Tontonoz $\mathrm{P}$, Zelcer N: The E3 ubiquitin ligase IDOL induces the degradation of the low density lipoprotein receptor family members VLDLR and ApoER2. J Biol Chem 2010, 285:19720-19726.

33. Lindholm D, Bornhauser BC, Korhonen L: Mylip makes an Idol turn into regulation of LDL receptor. Cell Mol Life Sci 2009, 66:3399-3402.

34. Zelcer N, Hong C, Boyadjian R, Tontonoz P: LXR regulates cholesterol uptake through Idol-dependent ubiquitination of the LDL receptor. Science 2009, 325(5936):100-104.

35. Weissglas-Volkov D, Calkin AC, Tusie-Luna T, Sinsheimer JS, Zelcer N, Riba L, Tino AM, Ordoñez-Sánchez ML, Cruz-Bautista I, Aguilar-Salinas CA, Tontonoz P, Pajukanta P: The N342S MYLIP polymorphism is associated with high total cholesterol and increased LDL receptor degradation in humans. J Clin Invest 2011, 121:3062-3071.

36. Santos PC, Oliveira TG, Lemos PA, Mill JG, Krieger JE, Pereira AC: MYLIP p. $\mathrm{N} 342 \mathrm{~S}$ polymorphism is not associated with lipid profile in the Brazilian population. Lipids Health Dis 2012, 11:83.

37. Banka CL: On male-specific estrogen action: good for the gander? J Am Coll Cardiol 2012, 59:418-419.

38. Kararigas G, Bito V, Tinel H, Becher E, Baczko I, Knosalla C, Albrecht-Küpper B, Sipido KR, Regitz-Zagrosek V: Transcriptome characterization of estrogentreated human myocardium identifies myosin regulatory light chain interacting protein as a sex-specific element influencing contractile function. J Am Coll Cardiol 2012, 59:410-417.

39. Ruixing $Y$, Dezhai $Y$, Shuquan L, Yuming $C$, Hanjun $Y$, Qiming F, Shangling $P$, Weixiong $L$, Jing $T$, Yiyang $L$ : Hyperlipidaemia and its risk factors in the Guangxi Bai Ku Yao and Han populations. Public Health Nutr 2009, 12:816-824

40. Wu DF, Yin RX, Aung LH, Hu XJ, Cao XL, Miao L, Li Q, Yan TT, Wu JZ, Pan SL: Polymorphism of rs1044925 in the acyl-CoA:cholesterol acyltransferase-1 gene and serum lipid levels in the Guangxi Bai Ku Yao and Han populations. Lipids Health Dis 2010, 9:139.

41. Miao L, Yin RX, Wu DF, Cao XL, Li Q, Hu XJ, Yan TT, Aung LH, Yang DZ, Lin WX: Peroxisome proliferator-activated receptor delta $+294 \mathrm{~T}>\mathrm{C}$ polymorphism and serum lipid levels in the Guangxi Bai Ku Yao and Han populations. Lipids Health Dis 2010, 9:145.

42. Cao XL, Yin RX, Wu DF, Miao L, Aung LH, Hu XJ, Li Q, Yan TT, Lin WX, Pan SL: Genetic variant of V825I in the ATP-binding cassette transporter A1 gene and serum lipid levels in the Guangxi Bai Ku Yao and Han populations. Lipids Health Dis 2011, 10:5.

43. Aung LH, Yin RX, Miao L, Hu XJ, Yan TT, Cao XL, Wu DF, Li Q, Pan SL, Wu JZ: The proprotein convertase subtilisin/kexin type 9 gene E670G polymorphism and serum lipid levels in the Guangxi Bai Ku Yao and Han populations. Lipids Health Dis 2011, 10:5

44. Liu WY, Yin RX, Zhang L, Cao XL, Miao L, Wu DF, Aung LH, Hu XJ, Lin WX, Yang DZ: Association of the LIPG 584C $>$ T polymorphism and serum lipid levels in the Guangxi Bai Ku Yao and Han populations. Lipids Health Dis 2010, 9:110.

45. People's Republic of China-United States Cardiovascular and Cardiopulmonary Epidemiology Research Group: An epidemiological study of cardiovascular and cardiopulmonary disease risk factors in four populations in the People's Republic of China. Baseline report from the P.R.C.-U.S.A. Collaborative Study. Circulation 1992, 85:1083-1096.

46. Ruixing $Y$, Shangling $P$, Shuquan L, Dezhai Y, Weixiong L, Qiming F, Yuming C, Yaoheng H, Yijiang Z, Qinchen L: Comparison of hypertension and its risk actors between the Guangxi Bai Ku Yao and Han populations. Blood Press 2008, 17:306-316.

47. Ruixing $Y$, Weixiong L, Hanjun $Y$, Dezhai $Y$, Shuquan L, Shangling P, Qiming $F$, Jinzhen W, Jianting G, Yaju D: Diet, lifestyle, and blood pressure of the middle-aged and elderly in the Guangxi Bai Ku Yao and Han populations. Am J Hypertens 2008, 21:382-387.

48. Zhou BF, Cooperative Meta-Analysis Group of the Working Group on Obesity in China: Predictive values of body mass index and waist circumference for risk factors of certain related diseases in Chinese adults-study on optimal cut-off points of body mass index and waist circumference in Chinese adults. Biomed Environ Sci 2002, 15:83-96.

49. Jeemon P, Pettigrew K, Sainsbury C, Prabhakaran D, Padmanabhan S: Implications of discoveries from genome-wide association studies in current cardiovascular practice. World J Cardiol 2011, 3:230-247.
50. Dong W, Ma X, Zhang D, Yu S: Effect of maize embryo on delaying aging. Food Sci 2002, 23:95-97.

51. Jenkins DJ, Kendall CW, Axelsen M, Augustin LS, Vusksan V: Viscous and nonviscous fibres, nonabsorbable and low glycaemic index carbohydrates, blood lipids and coronary heart $d$ isease. Curr Opin Lipidol 2000, 11:49-56.

52. Weggemans RM, Trautwein EA: Relation between soy-associated isoflavones and LDL and HDL cholesterol concentrations in humans: a meta-analysis. Eur J Clin Nutr 2003, 57:940-946.

53. Zhan S, Ho SC: Meta-analysis of the effects of soy protein containing isoflavones on the lipid profile. Am J Clin Nutr 2005, 81:397-408.

doi:10.1186/1476-511X-11-141

Cite this article as: Yan et al:: Association of MYLIP rs3757354 SNP and several environmental factors with serum lipid levels in the Guangxi Bai $\mathrm{Ku}$ Yao and Han populations. Lipids in Health and Disease 2012 11:141.

\section{Submit your next manuscript to BioMed Central and take full advantage of:}

- Convenient online submission

- Thorough peer review

- No space constraints or color figure charges

- Immediate publication on acceptance

- Inclusion in PubMed, CAS, Scopus and Google Scholar

- Research which is freely available for redistribution 